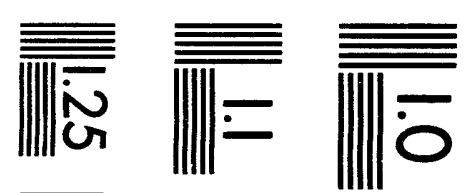

$$
\begin{aligned}
& \text { Fi }
\end{aligned}
$$

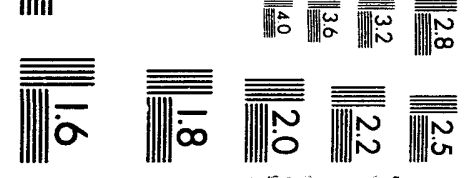



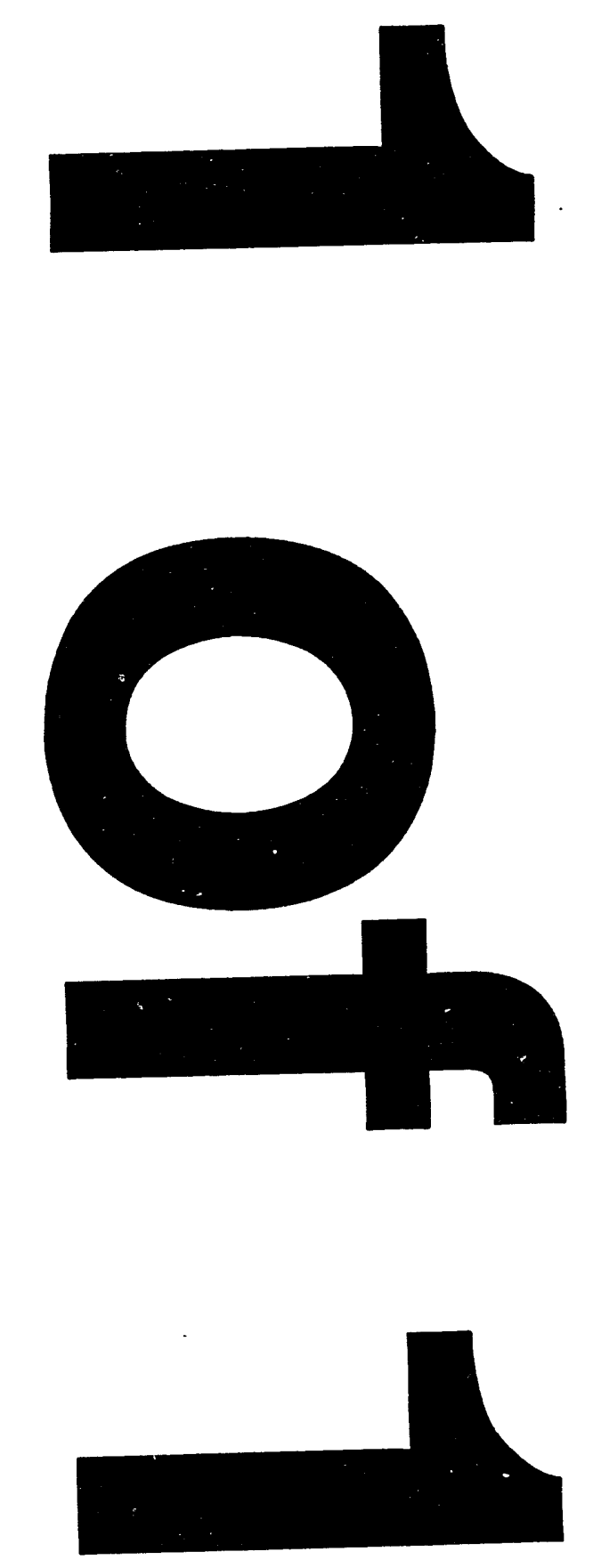
Contract Numbers:

DOE DE-AC2292PC91343 \&

OCDO CDO/R-90-21

Project Title:

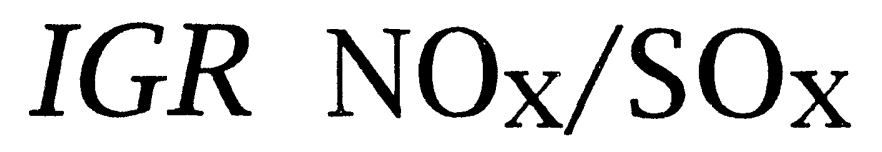

\section{Control Technology}

Reporting Period: $\quad$ 7/1/93 through 9/30/93

Due Date:

October 30, 1993

Contractor Name:

IGR Enterprises

11000 Cedar Avenue

Cleveland, Ohio 44106

(216) $721-5511$

Project Start:

September 25, 1992

Project Completion:

September 24, 1997

Approach Changes: $\quad$ None 
Contract Numbers: $\quad$ DOE DE-AC2292PC91343

$\&$

OCDO CDO/R-90-21

Project Thite: $I G R$ NOx/SOx
Control Technology

Reporting Period:

7/1/93 through $9 / 30 / 93$

Due Date:

October 30, 1993

Contractor Name:

$I G R$ Enterprises

11000 Cedar Avenue

Cleveland, Ohio 44106

(216) 721-5511

\section{Project Start:}

Project Completion:

Approach Changes:
September 25, 1992

September 24, 1997

\section{DISCLAIMER}

This report was prepared as an account of work sponsored by an agency of the United States Government. Neither the United States Government nor any agency thereof, nor any of their employees, makes any warranty, express or implied, or assumes any legal liability or responsibility for the accuracy, completeness, or usefulness of any information, apparatus, product, or process disclosed, or represents that its use would not infringe privately owned rights. Reference herein to any specific commercial product, process, or service by trade name, trademark, manufacturer, or otherwise does not necessarily constitute or imply its endorsement, recommendation, or favoring by the United States Government or any agency thereof. The views and opinions of authors expressed herein do not necessarily state or reflect those of the United States Government or any agency thereof. 


\section{Performance Variances,}

\section{Accomplishments, or Problems:}

\section{SUMMARY}

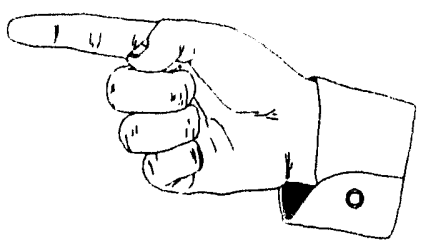

This reporting term covers the second full quarter subsequent to the program kick-off meeting and the DOE authorization to proceed with the contract work. During the term of this report substantial progress was made in two areas critical to the IGR NOx/SOx control technology. First, an acceptable methodology was developed for the preparation of the selective electrocatalysts required for $\mathrm{NOx} / \mathrm{SOx}$ destruction. Second, a clear and reproducible destruction of both SOx and NOx was achieved in separate tests using electrocatalysts prepared by the current methodology.

\section{DISCUSSION}

The Task 4 work was conducied using a yttria stabilized zirconia pellet with gold electrodes as the model system. This model system is similar to the types of materials we anticipate using in the final technology development. The gases used in the calibration work were industrial grade argon and nitrogen containing various levels of oxygen as further described below. The importance of doing this scaling and calibration work is that it will give us a benchmark to 
which we can compare our electrical data when NOx and SOx are introduced to the system.

We experimentally observed that the concentration of oxygen in the flowing gas stream had a significant effect on the steady state diffusion limited current that was measured. An example of this is seen for a test run in flowing industrial grade argon. (This grade of argon is commonly contaminated with roughly 50 ppm $\mathrm{O}_{2}$, the argon component of the gas stream is electrochemically inactive).

Figure 1 is a current versus time plot immediately after the periodic voltage was applied to the system. Previous to this test the sample had been at open circuit for a period of tens of minutes allowing for any oxygen gas concentration gradient at the cathode to collapse and the cathodic (reducing) surface to equilibrate with the passing gas stream. The peak current observed in this experiment was about $58 \mathrm{~mA}$ which very slightly degrades to about $55 \mathrm{~mA}$ during the balance of the power on portion of a given cycle. The latter value is about $95 \%$ of the initial value.

The relatively insignificant decay of the current under these circumstances suggests that the concentration gradient at the cathode is formed to an negligible degree under these conditions over a term on the order of a few seconds. About ten seconds later a second set of readings were made and the current versus time plot is shown in Figure 2. The only difference in the two sets of data is the ten or so seconds which have elapsed as the computer drove the system with the 
listed waveform. In this second set of data the peak current remains at abolit $58 \mathrm{~mA}$, however the nominal steady state current now decays to about $22 \mathrm{~mA}$, a value which is only $38 \%$ of the initial reading. This may be compared to the initial electrochemical data (Figure 1) wherein the current decayed very slightly (95\%). The observed behavior of Figure 2 was maintained over the next two hours. It is apparently the true steady state behavior of this system under these conditions of flow, concentration, and temperature. This data shows that an oxygen concentration gradient develops over a term of about 10 seconds at the surface of the sample. This gradient then becomes the limiting current factor.

To further understand the quantitative effects of oxygen partial pressure on the electrochemical performance the gas stream was changed to $10,000 \mathrm{ppm}(1 \%)$ oxygen in nitrogen. This amounts to a nominal increase in the oxygen partial pressure of $200 \mathrm{X}$. Figures 3 and 4 give the current versus time plots for 10,000 ppm O2 (1\%) in nitrogen. Note that the limiting currents are reached very quickly and are a full $84 \%$ of the peak values, this is because the high level of oxygen gas results in a very shallow gradient. In summary, the data seems to indicate that we are electrochemically creating an oxygen concentration gradient at the surface of the sample and that this gradient is dependent on the amount of oxygen present in the bulk gas stream, the duty cycle, and the time elapsed. 


\section{THEORETICAL CONSIDERATIONS}

This data may be evaluated in light of theoretical considerations for transport in electrode processes. For the case of linear diffusion in the gas phase the limiting diffusion current density is given by the Cottrell equation:

$$
\mathrm{j}=-\mathrm{nFCo} \mathrm{ox}_{\mathrm{ox}}\left\{\mathrm{D}_{\mathrm{ox}} / \pi \mathrm{t}\right\}^{1 / 2}
$$

where $\mathrm{j}$ is the current density, $\mathrm{n}$ is the number of electrons transferred per mole (4 for $\mathrm{O}_{2}$ ), $\mathrm{F}$ is Faraday's constant, $\mathrm{Co}_{\text {ox }}$ is the partial pressure of oxygen in the bulk gas, $\mathrm{D}_{\mathrm{ox}}$ is the diffusion constant for the reactive species and $t$ is the time elapsed.

For the case of convective diffusion in the gas phase the limiting diffusion current density is given by the Ilkovic equation:

$$
j=-n F C o_{0 x}\left\{7 D_{0 x} / 3 \pi t\right\}^{1 / 2}
$$

where the symbols have the same meaning as the above case.

Note that in both types of diffusional controlled transport the current at a given moment in time is proportional to the initial partial pressure of oxygen in the gas stream and that the current density approaches its limiting value asymptotically as the square root of the time elapsed. The data we observed appear to be in agreement with these theoretical considerations. 


\section{ELECTROCATALYST PREPARATION}

Task 2 of the Statement of Work addresses the preparation of a suitable electrocatalytic surface for the ceramic electrolyte. Both water based and organic solvent based transition metal oxide electrocatalyst systems were formulated. This work built upon IGR's pre-contract knowledge in combination with better processing facilities and recent public literature.

Preparation of the electrocatalytic surface requires sintering (or heating) of the catalyst mixture after application to the ceramic surface. A variety of sintering temperatures and atmospheres were tested for the preparation. The focus of this work was to have a catalyst surface that was well bonded and maintain a high surface area. Temperature was varied between $450^{\circ} \mathrm{C}$ and $1400^{\circ} \mathrm{C}$. Air, $4 \%$ oxygen, and argon were used as the atmosphere for sintering. It was found that lower sintering temperatures resulted in catalyst/ceramic systems that were not well bonded. Processing at $1400^{\circ} \mathrm{C}$ resulted in adequate bonding of the organic based systems. Water based electrocatalyst systems tended to spalled from (fall off) the ceramic electrolyte at all processing temperatures examined. This also caused removal of some of the ceramic electrolyte. Alteration of sintering atmosphere had only a secondary effect on the bonding behavior of the electrocatalyst. To maintain a high surface area for the electrocatalyst a low reactivity, high surface area, electrocatalyst particles have been added to some of the organic based systems. 
SULFUR DIOXIDE DESTRUCTION

A number of tests were run using yttria stabilized pellets surface treated with electrocatalyst to remove $\mathrm{SO}_{2}$ gas from an oxygen-free carrier gas. This work was conducted using a yttria stabilized zirconia pellet with gold electrodes as the model system and feed gases of nitrogen containing a preset level of (either $\mathrm{NO}$ or) $\mathrm{SO}_{2}$. The concentration of the contaminant gas was monitored by regular periodic analysis of the entrance and exit streams from the electrochemical reactor using an FT-IR (Fourier Transform Infra-Red) spectrophotometer.

The response of the test pellet to a straight DC current (Task 2) was established first. The voltage was held constant for 1 hour at each of the following voltages: $0.3 \mathrm{~V}, 0.5 \mathrm{~V}, 0.7 \mathrm{~V}, 1.0 \mathrm{~V}, 1.3 \mathrm{~V}, 1.7 \mathrm{~V}$. During these tests, the pellet temperature was maintained at $6500^{\circ} \mathrm{C}$. In all cases, negligible reduction in $\mathrm{SO}_{2}$ was noted. When the temperature was increased to $700^{\circ} \mathrm{C}$ a significant reduction in the level of $\mathrm{SO}_{2}$ was observed when the voltage was held at $1.7 \mathrm{~V}$. The feed gas was nitrogen containing $500 \mathrm{ppm} \mathrm{SO} 2$ flowing at $20 \mathrm{sccm}$ (about 65 accm). No oxygen was present in the gas stream. The results show a $70 \%$ reduction of $\mathrm{SO}_{2}$. Table 1 summarizes these results. 
TABLE 1

Destruction of $\mathrm{SO}_{2}\left(700{ }^{\circ} \mathrm{C}\right)$

Time (min.)

0

5

8

12

15
$\mathrm{SO}_{2}(\mathrm{ppm})$

500

390

285

180

150
$\%$ reduction

22

43

64

70

The $\mathrm{SO}_{2}$ level remained at $150 \mathrm{ppm}$ for several hours after which the $\mathrm{SO}_{2}$ level was observed to rise up to about $400 \mathrm{ppm}$. When the pellet was subsequently examined after the test it was observed to be cracked. A second pellet was tested under conditions of $650^{\circ} \mathrm{C}$ with $500 \mathrm{ppm}$ of $\mathrm{SO}_{2}$ and no oxygen present. This resulted in a reduction $\mathrm{SO}_{2}$ of about $25 \%$ which was maintained for 24 hours. The test was terminated when the gold film electrodes on the pellet were observed to delaminate.

\section{NITROGEN OXIDE(S) DESTRUCTION}

A number of tests were run using yttria stabilized samples treated with an electrocatalyst to effectively remove NO gas from a carrier gas. This work was conducted using eight mole percent yttria fully stabilized zirconia as the solid ceramic electrolyte with thin porous gold film electrodes. The concentration of the $\mathrm{NO}$ and $\mathrm{NO}_{2}$ in 
the gas was monitored by periodic analysis of the gas stream by the FTIR (Fourier Transform Infrared) spectrometer. All of the tests described below are directly called for by Tasks 3 and 4 of the statement of work and are summarized in Table 2.

Before the test results are discussed it is important to understand the nature of the spectra which are collected by the FTIR. When dilute nitric oxide (NO in nitrogen) enters into the FTIR optical cell, one standard infrared gas phase "P-Q-R" peak is seen centered around $1875 \mathrm{~cm}^{-1}$ (Figure 5). When oxygen is added to the gas stream there is a spontaneous thermodynamic equilibrium established downstream of the electrochemical reactor within the FTIR optical cell between the $\mathrm{NO}$ and the oxygen to form some $\mathrm{NO}_{2}$. This results in both the $\mathrm{NO}_{2}$ and NO peaks appearing in the spectra. $\mathrm{NO}_{2}$ has a P-Q-R absorption peak centered at $1610 \mathrm{~cm}^{-1}$ (Figure 6). Because of this spontaneous equilibrium between $\mathrm{NO}, \mathrm{O}_{2}$ and $\mathrm{NO}_{2}$ (when oxygen is present in the gas stream) it is more accurate to report "total NOx" removal and not just "NO" removal.

The areas under the P-Q-R peaks seen in FTIR spectra measure the infrared absorbency of the gases present in the gas stream (peak area is proportional to the gas concentration.) Note that the IR absorbency of the gas also depends on the extinction coefficient for that gas. Since $\mathrm{NO}_{2}$ has a much higher extinction coefficient in the infrared than $\mathrm{NO}$, a much larger peak area will be seen for $\mathrm{NO}_{2}$ than NO when both gases are at equal concentrations. The spectra in Figure 6 shows two approximately equal peak areas for a gas stream in 
which $\mathrm{NO}$ reacts with oxygen to form $\mathrm{NO}_{2}$, although the $\mathrm{NO}_{2}$ (50-100 ppm range) and NO (450 to $500 \mathrm{ppm}$ range) concentrations are significantly different. In general, bent (not linear) triatomic molecules such as $\mathrm{NO}_{2}$ and $\mathrm{H}_{2} \mathrm{O}$ have much larger IR extinction coefficients than diatomic molecules such as NO or $\mathrm{CO}$.

The first tests was conducted with a feed gas was 500 ppm NO in nitrogen at a flow rate of $20 \mathrm{sccm}$. No oxygen was intentionally added to the gas stream. The pellet tester was maintained at $600^{\circ} \mathrm{C}$. After 15 minutes the NO was reduced by $71 \%$. During the next four hours the rate of NO removal remained at $71 \%$. Test 2 was conducted in an environment of $500 \mathrm{ppm}$ NO with no oxygen present at a temperature of $5000^{\circ} \mathrm{C}$. It resulted in $60-70 \% \mathrm{NO}$ removal. When $0.4 \%$ oxygen was added to the gas stream, the NO removal decreased to about $20 \%$. This drop in NO removal with the addition of oxygen is consistent with the ideas that oxygen gas competes with NO for electrocatalyst active sites at the surface of the specimen. Increasing the temperature to $600^{\circ} \mathrm{C}$ did not improve the percentage of NO removed.

Test 3 used a sample to which the electrocatalyst had been sintered at $1350^{\circ} \mathrm{C}$. The test temperature was $900^{\circ} \mathrm{C}$ and the gas used was 500 ppm NO, with no oxygen present. This resulted in $80 \%$ NO removal. Test 4 used a specimen identical to the specimen used in Test 2 at a temperature of $500^{\circ} \mathrm{C}$. The test gas was composed of 450 ppm NO and $0.4 \%$ oxygen. Approximately $25 \% \mathrm{NO}_{\mathrm{x}}$ reduction over a continuous term of several hours was noted. 
Test 5 used a specimen identical to Test 3. The initial test conditions were $900^{\circ} \mathrm{C}$ in a gas of $450 \mathrm{ppm} \mathrm{NO}$ and $0.4 \%$ oxygen. NOx removal rates of $70-80 \%$ were recorded. After the test was completed the specimen was examined and the Au electrodes showed significant sintering and shrinkage which greatly reduced the amount of active surface. Only those electrocatalytic areas that are directly overlaid with porous conductive electrode are significantly active in the removal of NO.

Table 2

Test \#

\section{1}

2

2

2

3

4

5
Temperature

$6000 \mathrm{C}$

$500 \mathrm{oC}$

$5000 \mathrm{C}$

$600 \circ \mathrm{C}$

$900 \circ \mathrm{C}$

$500 \mathrm{oC}$

$9000 \mathrm{C}$
\% Oxygen \% NOx Removed

0

$71 \%$

$70 \%$

$0.4 \%$

$20 \%$

$0.4 \%$

$20 \%$

0

$80 \%$

$0.4 \%$

$25 \%$

$0.4 \%$

$75 \%$ 
Open Items: None

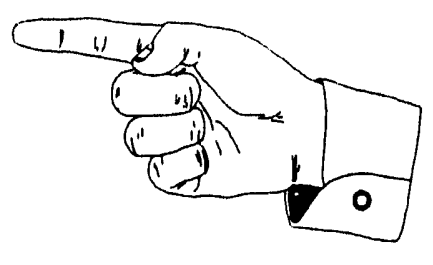

\section{Status Assessment \& Forecast:}

The work is going well with no problems foreseen at this time. Further work in the

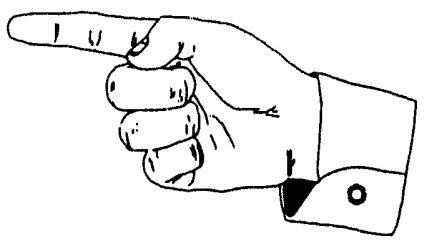
upcoming months will principally involve the Task 2 and Task 4 study of NOx and SOx containing gas streams in the presence of excess oxygen. Work will continue on the electrocatalyst testing. The overall goal remains the screening of electrocatalysts for good NOx/SOx removal at acceptable power costs.

\section{Key Personnel Staffing Report:}

Dr. Arnold Z. Gordon, the president of IGR, has spent during this quarter 360.50 hours on this contract.

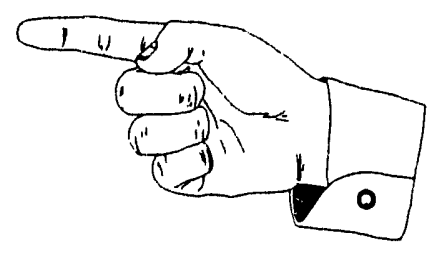




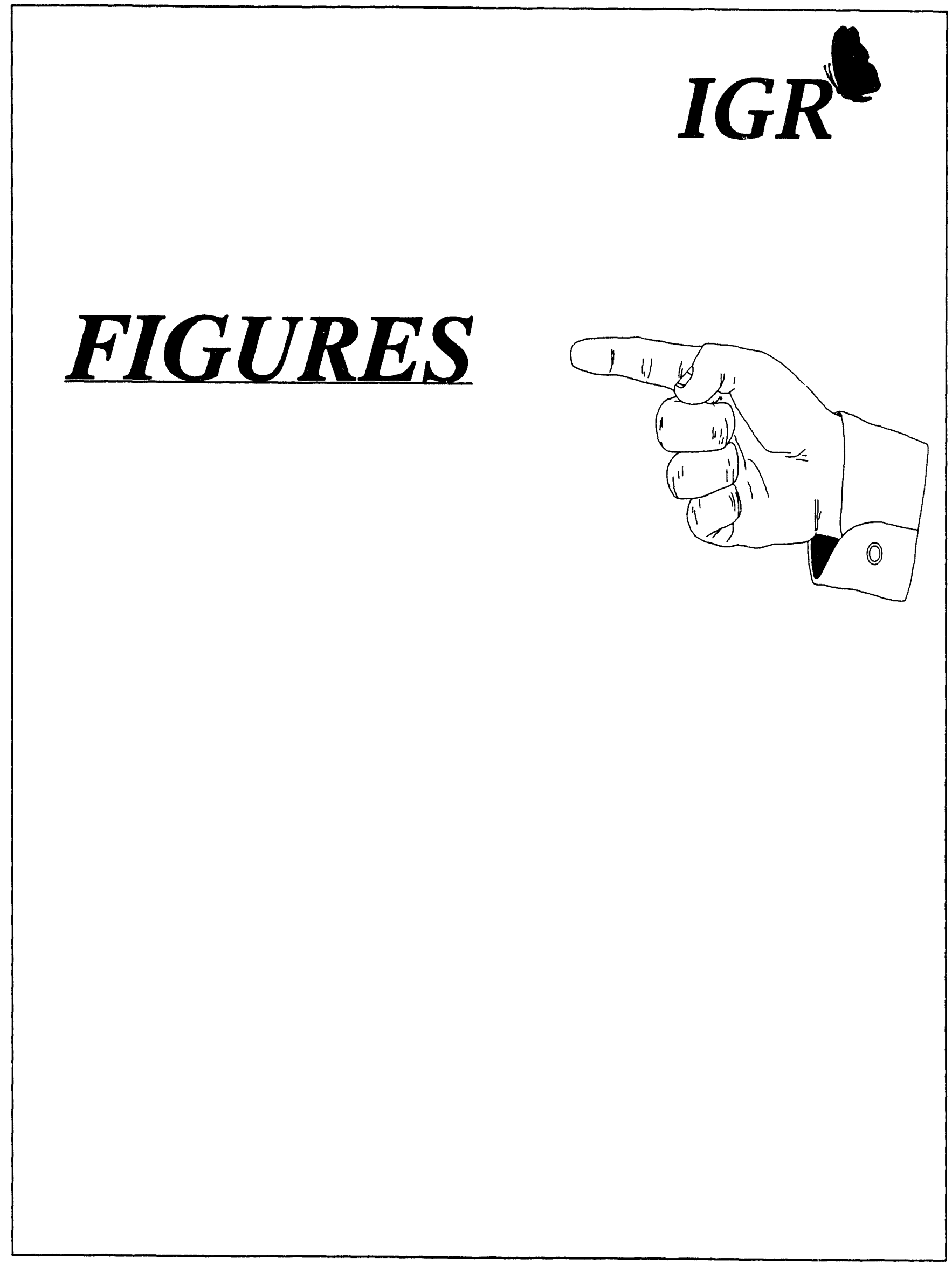


Figure 1

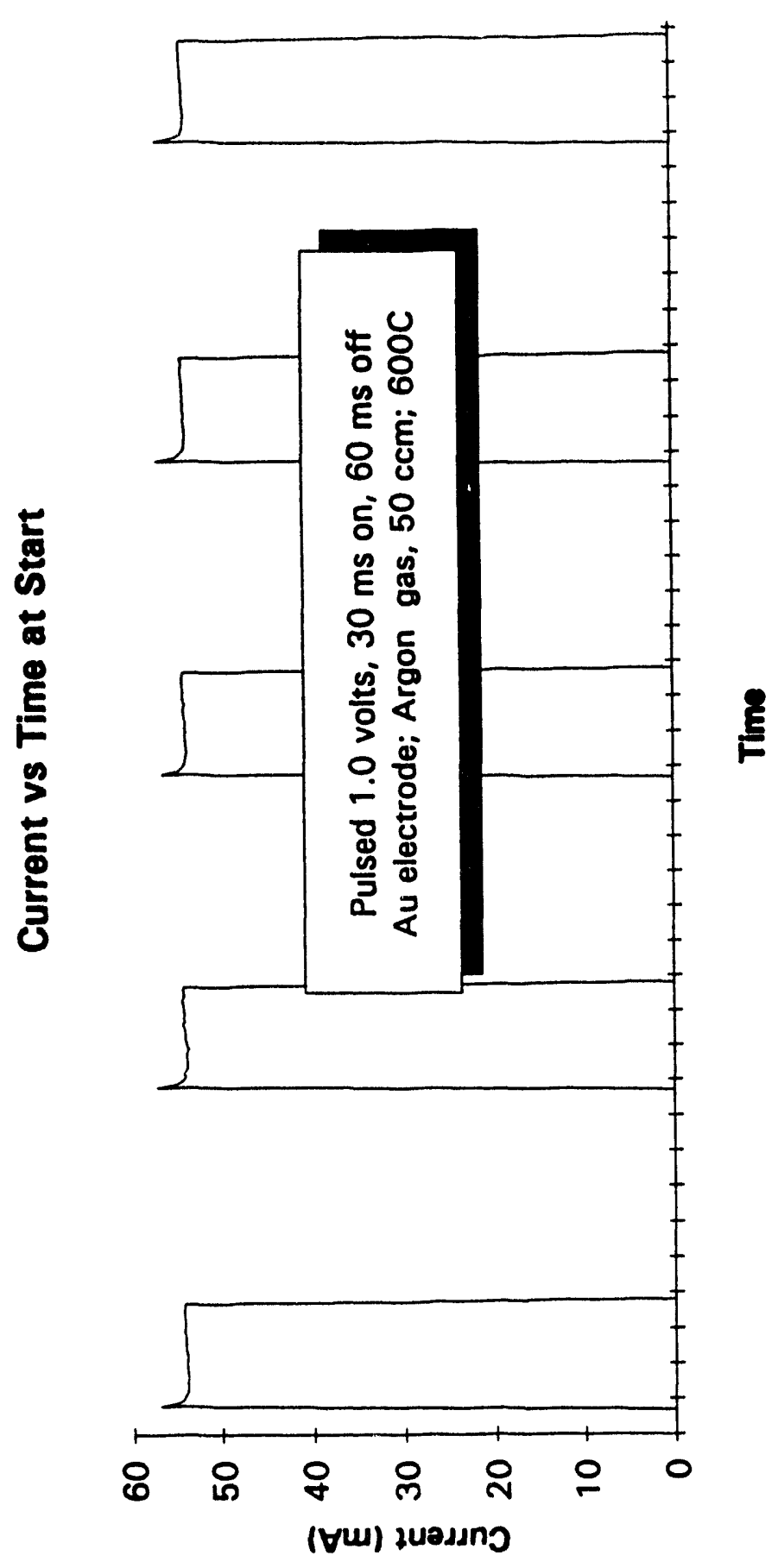


Figure 2

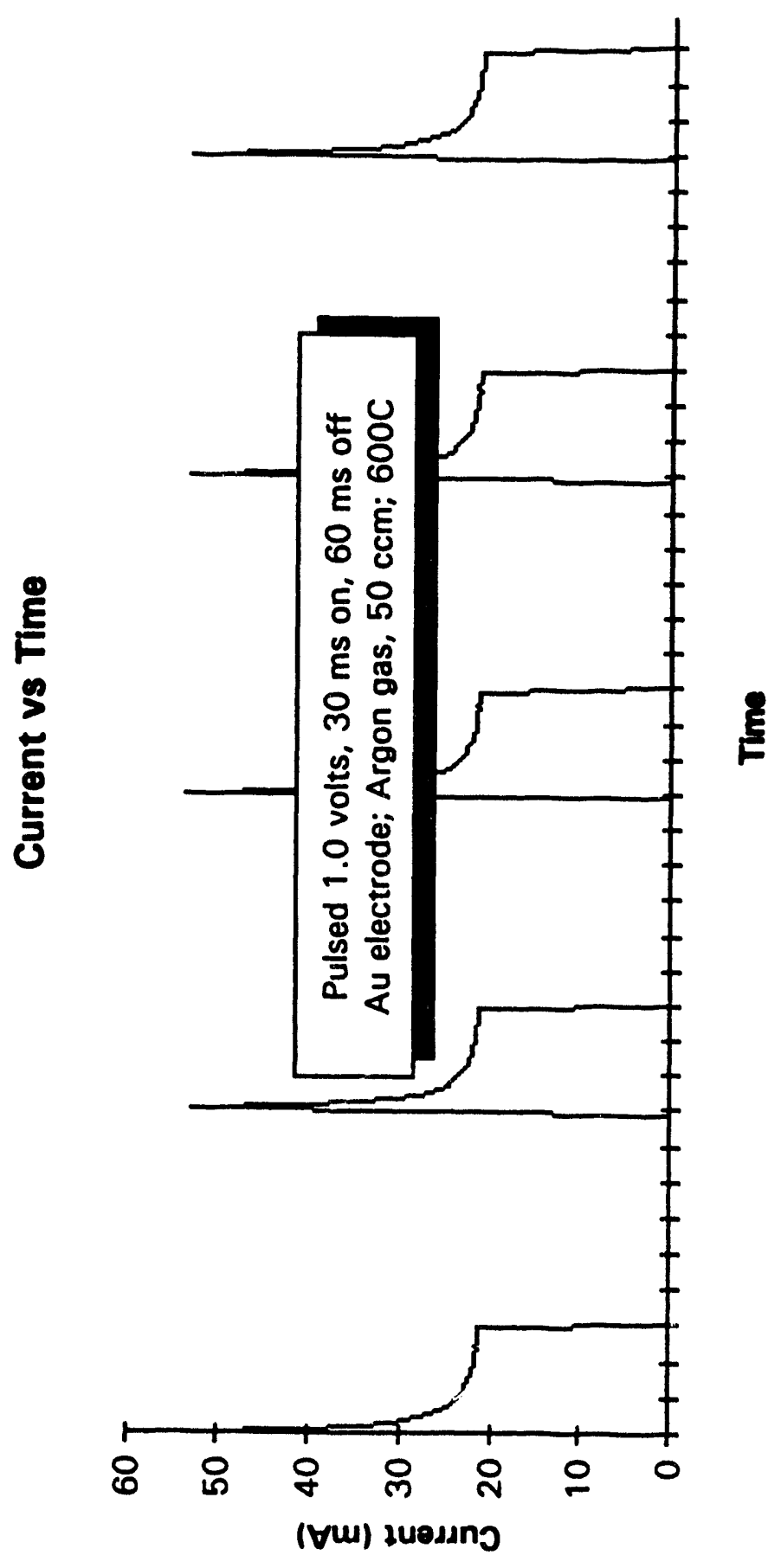


Figure 3

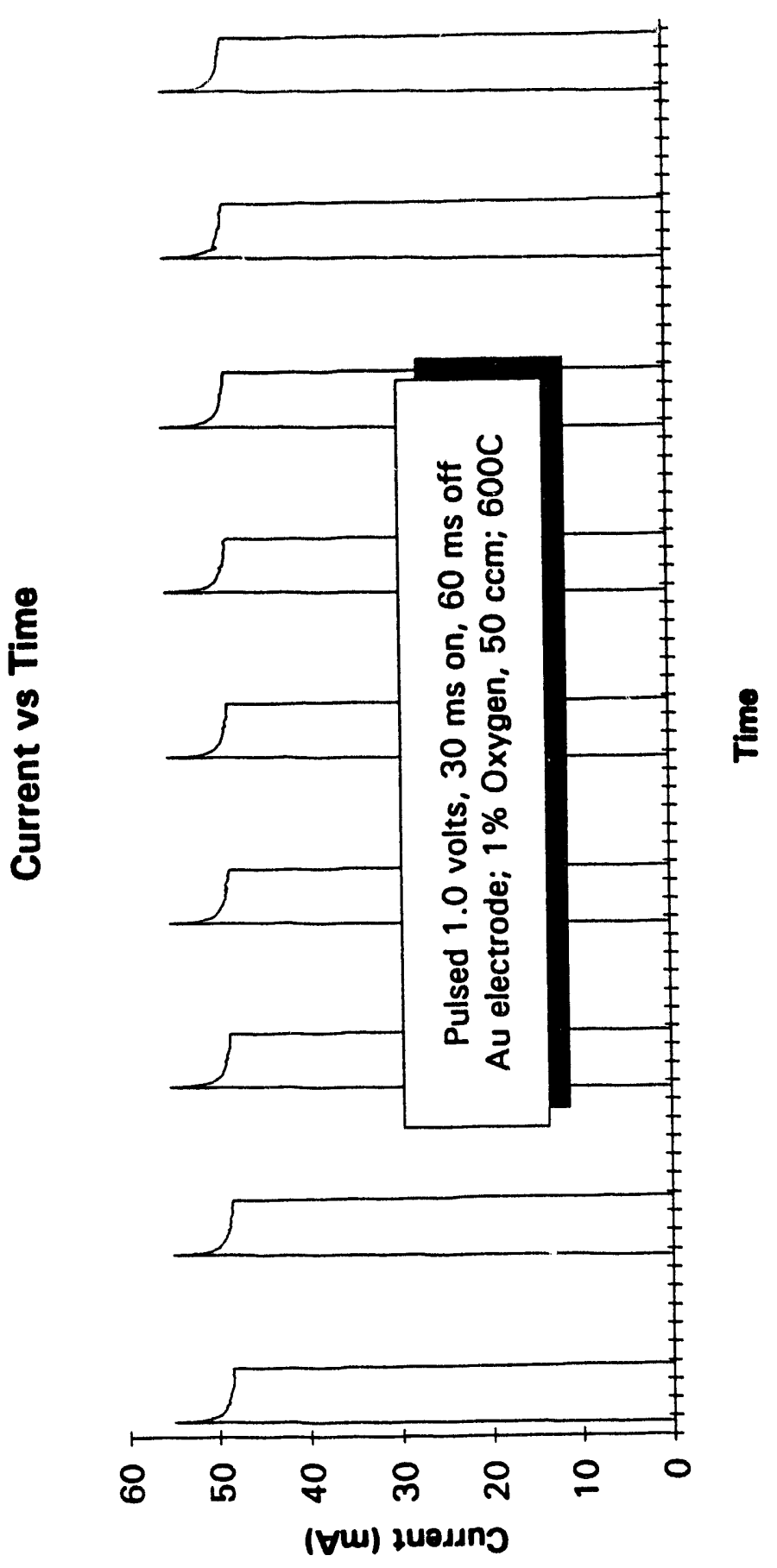


Figure 4

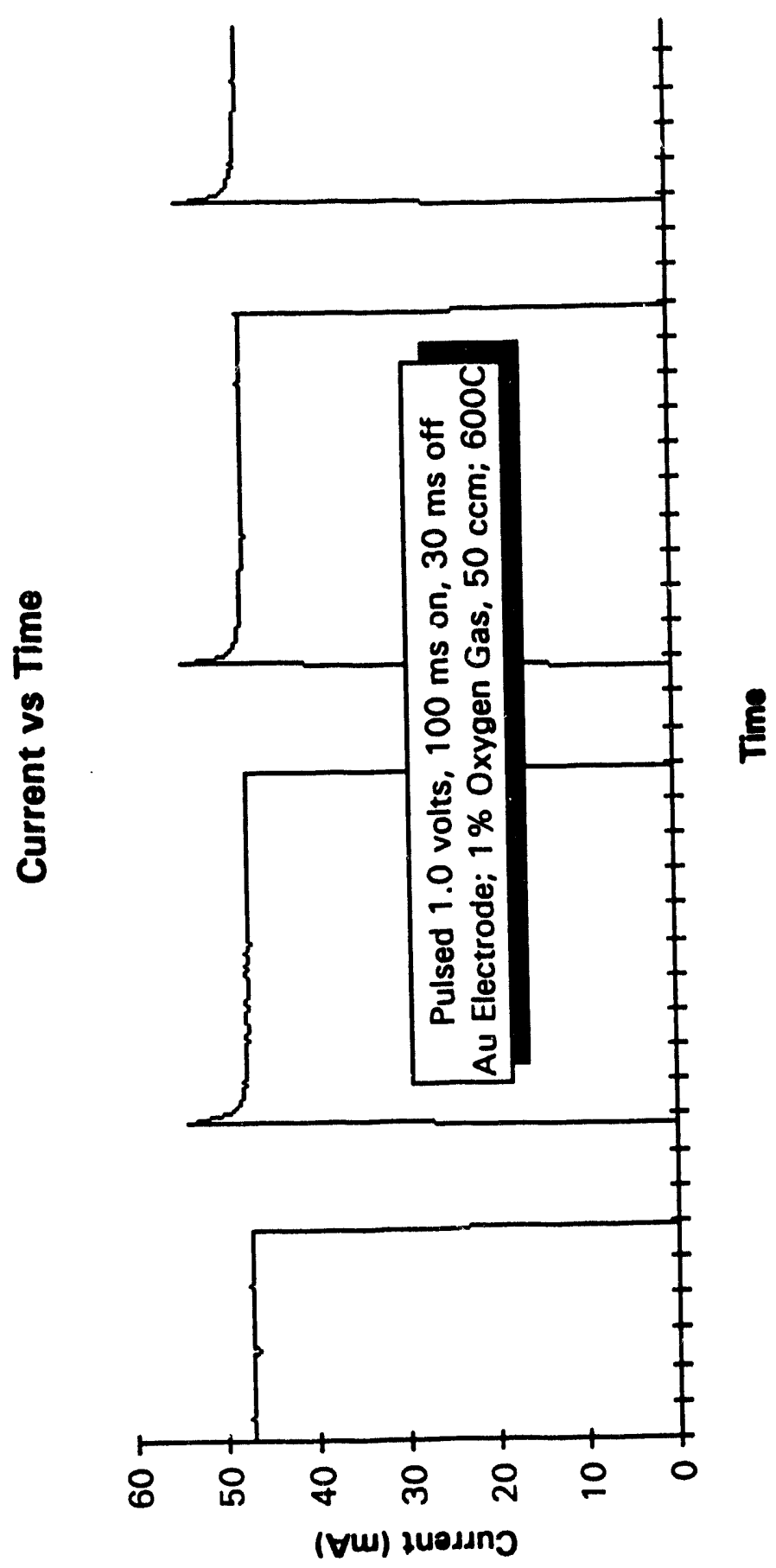




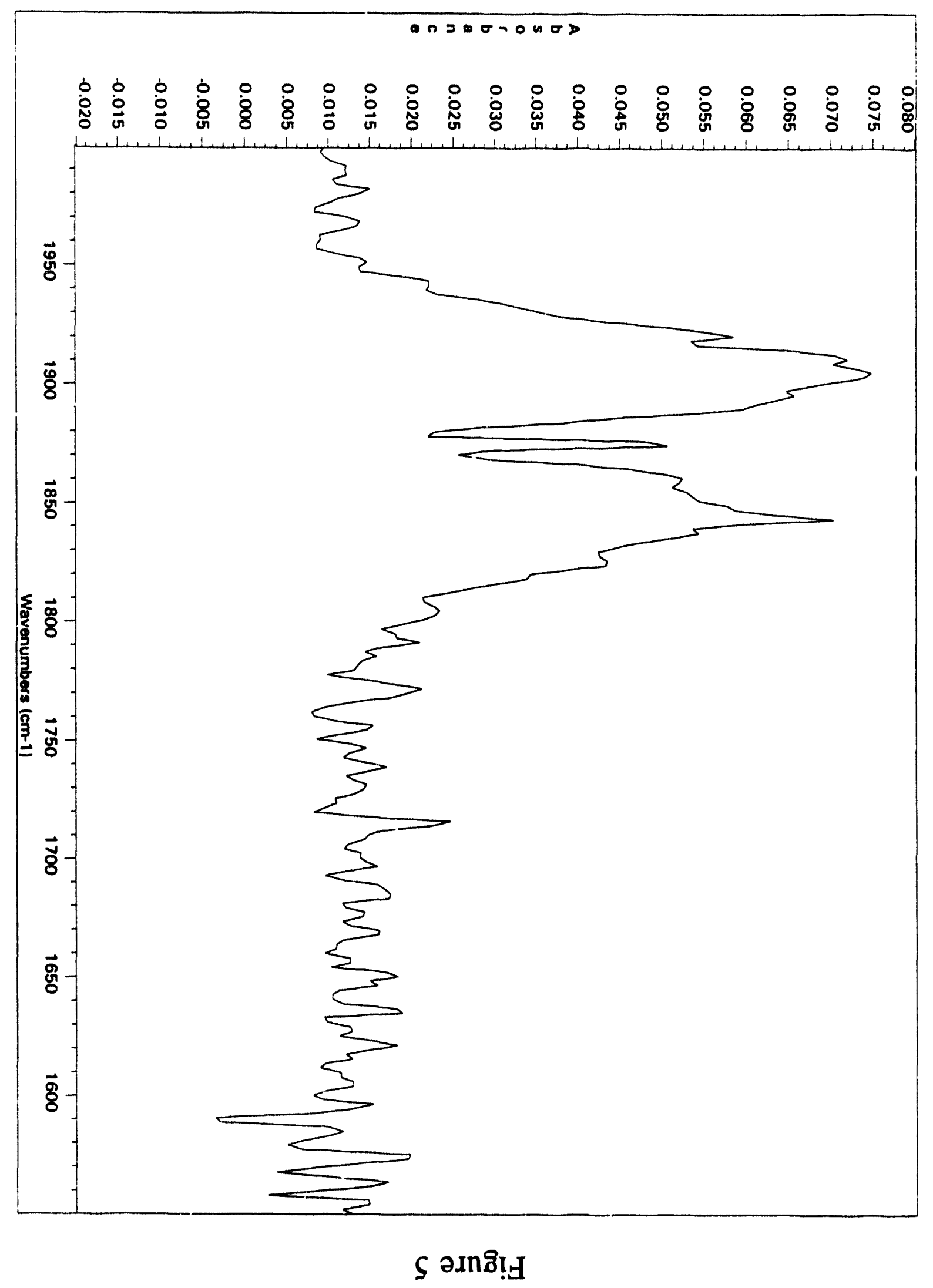


Figure 6

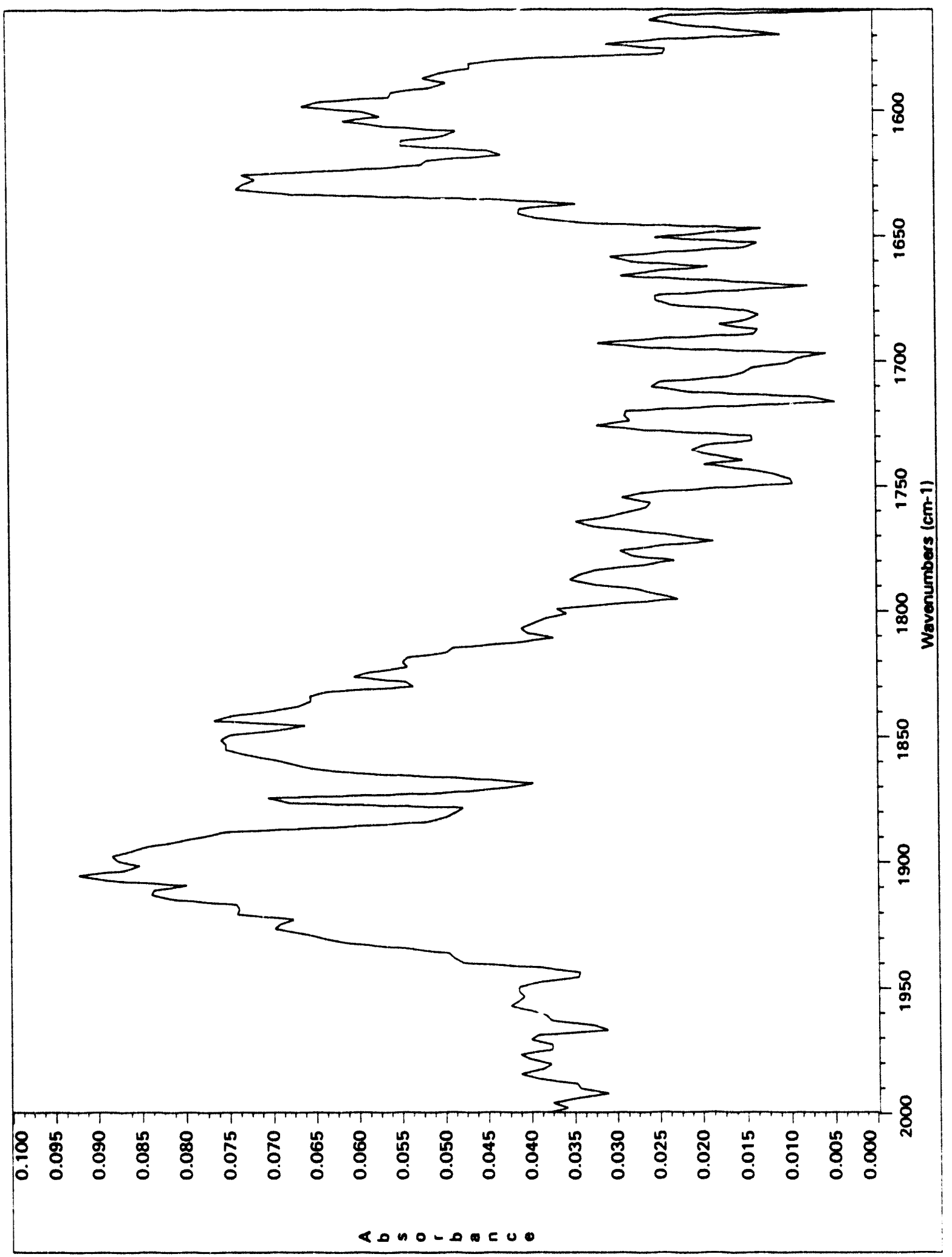




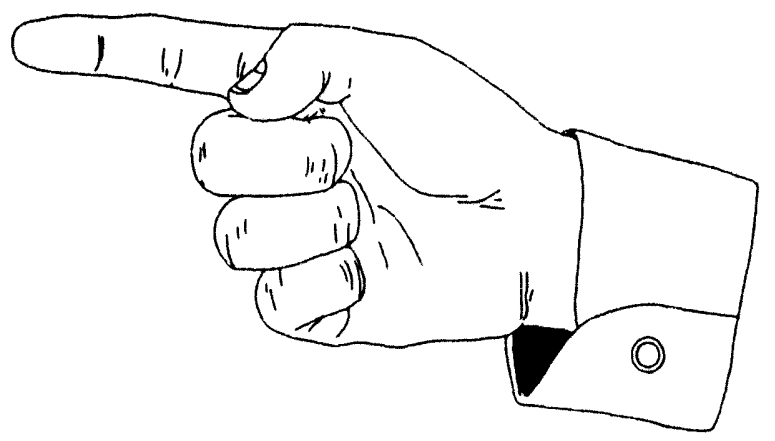



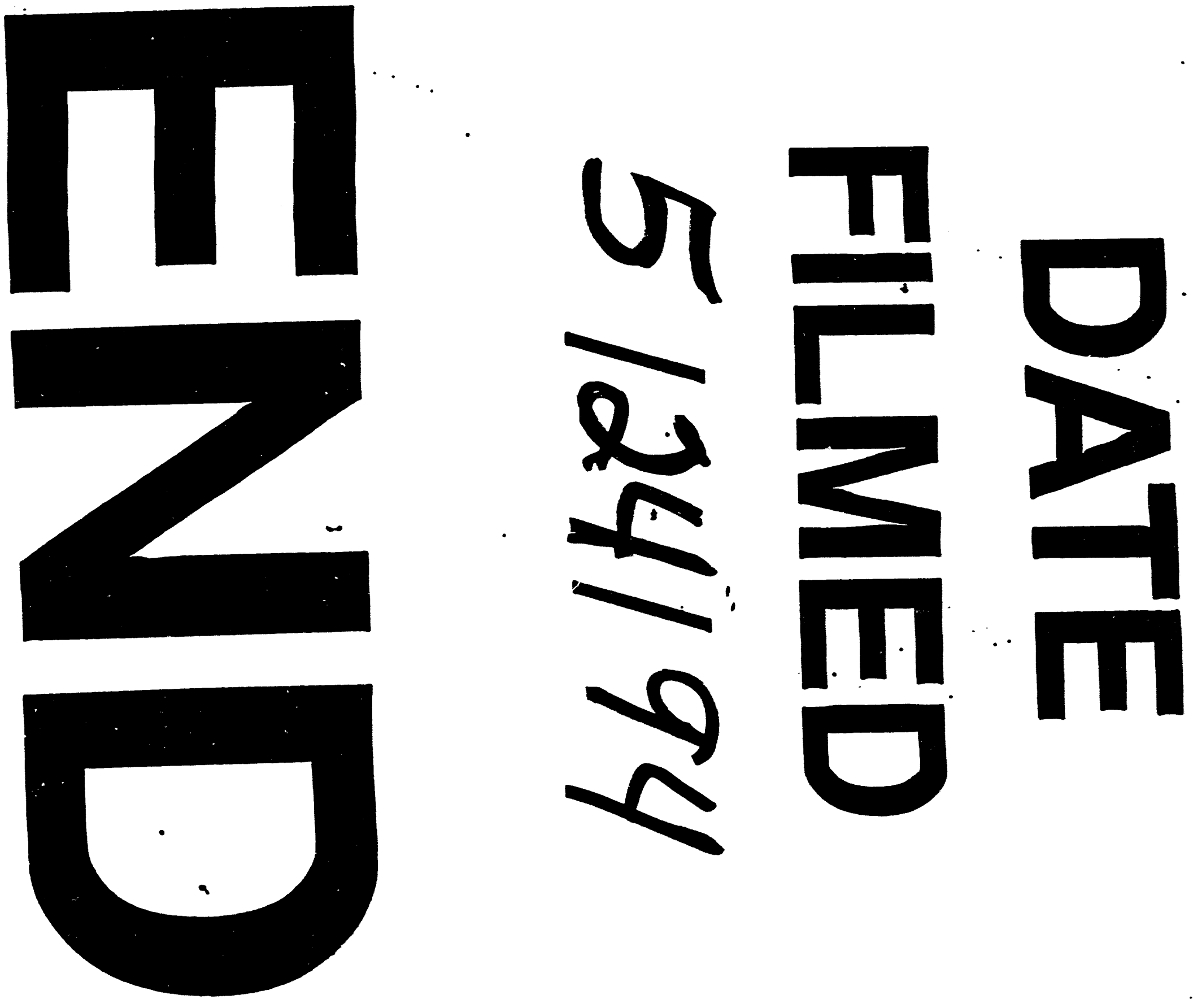
